\title{
Editorial
}

\section{What Is New about New Antidepressants?}

\author{
Steven L. Dubovsky \\ Department of Psychiatry, State University of New York at Buffalo, Buffalo, NY, USA; Departments of Psychiatry and \\ Medicine, University of Colorado, Denver, CO, USA
}

Depressed patients and their physicians naturally expect that each new antidepressant that reaches the market will represent a conceptual and therapeutic advance over previous medications. We can determine how realistic this expectation may be if we review dispassionately the validity of the assumptions that underlie the development of new antidepressants and the data supporting their differential effectiveness.

\section{Do Antidepressants Work?}

Despite claims to the contrary, research indicates that as a class antidepressants are effective for depression, regardless of severity [1]. It has been proposed that more recent, larger studies have found a lower rate of effectiveness of antidepressants mainly because an increasing placebo response rate [2,3] results in smaller effect sizes [4]. However, a systematic review of 252 placebo-controlled antidepressant trials found that since 1991 the placebo response rate has remained constant at around 35-40\% [5]. A 2018 systematic review and network meta-analysis of 522 published and unpublished double-blind, randomized controlled trials (RCT) found that all antidepressants were more effective than placebo [4], with overall OR of 1.66 for response and 1.56 for remission [6]. A 10-year Danish study demonstrated that most patients treated for

\section{KARGER}

() 2018 S. Karger AG, Basel

E-Mail karger@karger.com

www.karger.com/pps moderate to severe depression do not require more than 2 years of treatment, although a distinct minority require ongoing specialty care [7]. One estimate is that antidepressants alone or with augmentation benefit $60-70 \%$ of patients with major depressive disorder (MDD) [8]. However, as discussed below, the finding that antidepressants are better than placebos at improving depression does not mean that they cure the total disorder [6].

\section{What Is the Therapeutic Action of Antidepressants?}

The proposal more than half a century ago that inhibition of synaptic norepinephrine reuptake by tricyclic antidepressants was the therapeutically relevant action [9] has continued to inform the development of new antidepressants, which are designed based on reuptake inhibition of monoamine neurotransmitters such as norepinephrine, serotonin, and dopamine. Following the introduction of the selective serotonin reuptake inhibitors (SSRI), hypotheses emerged that altering serotonergic neurotransmission, via the transmitter and/or its receptors, made them more "selective" for MDD or specific MDD subtypes [10]. With the advent of serotonin-norepinephrine reuptake inhibitors and triple (serotonin, norepinephrine, dopamine) reuptake inhibitors [11], manufacturers speculated that such "broad-spectrum" 
actions made these antidepressants preferable for certain depressed patients [12].

The therapeutic relevance of an effect on a particular neurotransmitter has increasingly been questioned. For one thing, there is a considerable lag between the delayed onset of clinical benefit and the immediate effects of antidepressants on neurotransmitter reuptake and receptors [13]. Several studies contradict the notion of spectra of antidepressant effects attributable to actions on different neurotransmitter systems. For example, the tricyclic antidepressant tianeptine increases the serotonin uptake acutely and chronically, but it is just as effective for MDD as the SSRI [14]. An analysis of data from two 8-week double-blind RCT comparing the norepinephrine reuptake inhibitor reboxetine with the SSRI fluoxetine in a total of 421 patients revealed no difference in effectiveness against all depressive symptoms individually or collectively [15]. Going further, a meta-regression of 104 randomized trials comparing antidepressant classes found no significant difference in efficacy between norepinephrine reuptake inhibitors, SSRI, serotonin-norepinephrine reuptake inhibitors, triple reuptake inhibitors, and serotonin $5 \mathrm{HT}_{2}$ receptor antagonists [16].

The monoamine theory of antidepressant effects is further limited by findings of an impact of all antidepressants not only on different neurotransmitters and neuromodulators but also on intracellular messengers, gene expression, neuronal viability, and synaptic plasticity. Ultimately, multiple discrete effects on one aspect or another of functions of and interactions between neurons, glial cells, and astrocytes are likely to result in changes in communication between networks of neurons that regulate emotion, thinking, and the stress response [17]. One such change alters depression-associated miscommunication between the default mode network (DMN), the salience network, and the central executive network [13]. The DMN, which consists of the ventromedial prefrontal cortex, the posterior cingulate cortex, the inferior parietal cortex, and the middle temporal lobe, mediates introspection and rumination. The salience network, which includes the anterior cingulate cortex, the insula, and the ventromedial prefrontal cortex, mediates processing of salient information from the external world. The central executive network, which includes the dorsolateral prefrontal cortex, mediates working memory and attention. Excessive connectivity between the DMN and other networks can orient attention toward internally generated negative affective states, with a reduced ability to respond appropriately to external contingencies. Restoration of normal connectivity would be expected to decrease the promi- nence of internal dysphoric states carried by the DMN and improve a patient's ability to process external stimuli. In a 10-week double-blind placebo-controlled (DBPC) study, duloxetine but not placebo reduced the excessive connectivity of the DMN with the other networks, and this correction was correlated with an antidepressant effect [18]. However, since the clinical effect of antidepressants like duloxetine occurs some time after observed physiologic changes, a causal correlation is not inevitable. One way to address this issue is with an antidepressant with a nearly immediate onset of action. In a comparison of intravenous ketamine and placebo in patients with MDD and controls [13], a rapid antidepressant response to ketamine in the depressed patients was accompanied by an equally rapid improvement of connectivity between the salience network and the DMN. Examples of some of the intracellular, interneuronal, and network effects of antidepressants are summarized in Figure 1 [17, 19-31].

\section{Are Newer Antidepressants Better?}

If putative actions of antidepressants do not identify clinically relevant differences in the treatment of depression, is there any evidence of superiority of newer antidepressants over previous agents or over each other? Recently released antidepressants have usually been compared to placebo, sometimes along with a single reference antidepressant, the majority of the time in manufacturersponsored trials. Newer antidepressants, some examples of which are noted in Table 1, differ in known neurotransmitter and receptor actions; mifepristone acts directly on the hypothalamic-pituitary-adrenal axis, albeit by antagonizing glucocorticoid receptors. No meaningful differences in effectiveness in the acute treatment of MDD have been found between these medications and each other or medications that were already on the market [32-39]. Vortioxetine is said to improve cognition more reliably than some other antidepressants, possibly independently of improvement of depression; however, sertraline, citalopram, escitalopram, duloxetine, desvenlafaxine, bupropion, reboxetine, tianeptine, and ketamine have also been found to improve similar cognitive domains [40, 41].

Several larger data analyses provide insight into the relative effectiveness of new antidepressants. A critical review of 234 studies of "good or fair quality" of second-generation antidepressants ( $77 \%$ funded by industry) included 118 head-to-head RCT in addition to observational studies involving more than 1,000 subjects who were followed for 12 weeks or more; a meta-analysis was conducted for 


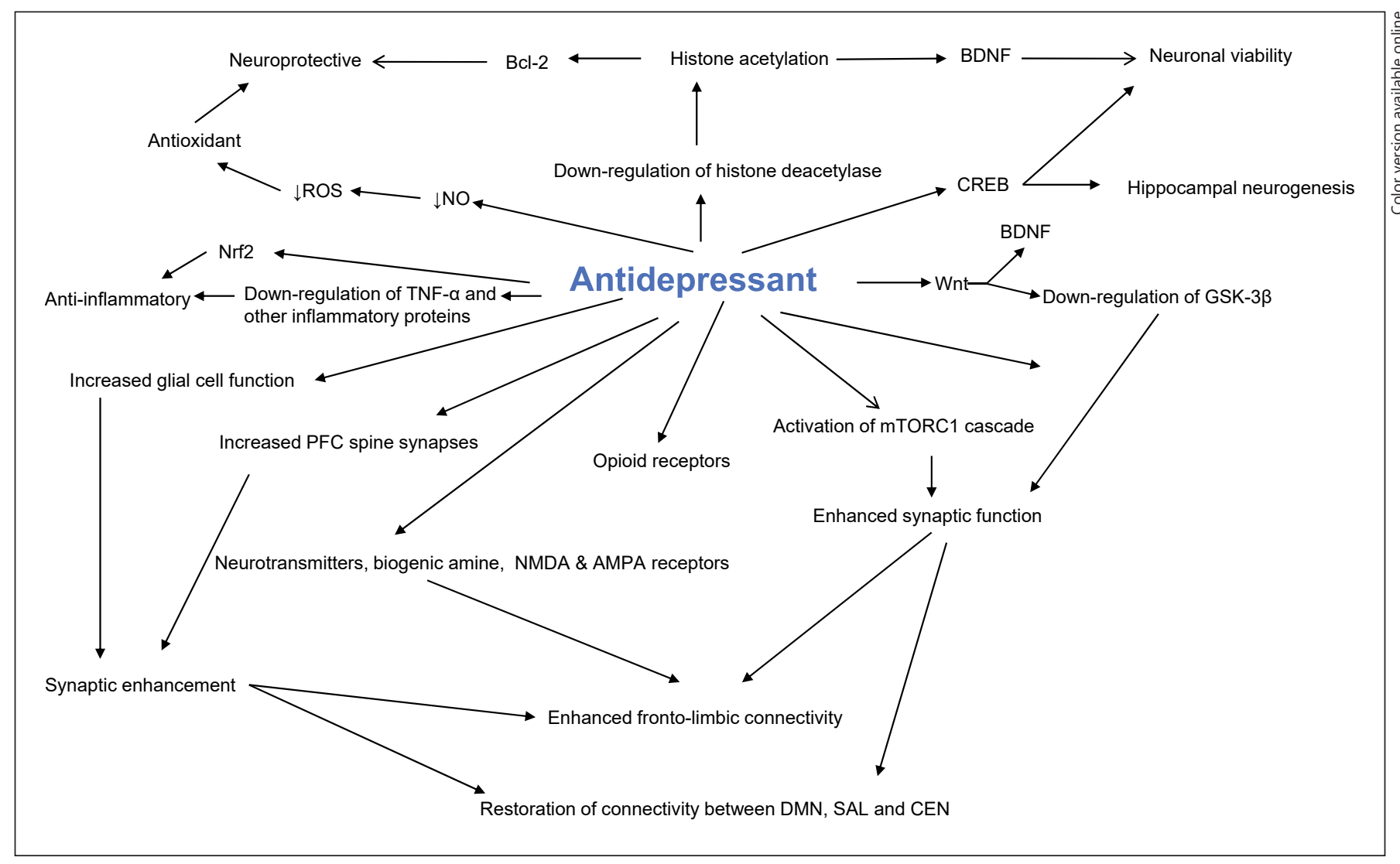

Fig.1.AMPA, a-amino-3-hydroxy-5-methyl-4-isoxazolepropionic acid; Bcl-2, B-cell lymphoma 2; BDNF, brain-derived neurotrophic factor; CEN, central executive network; CREB, cAMP-reactive element-binding protein; DMN, default mode network; GSK3, glycogen synthase kinase 3; MAPK, mitogen-activated protein ki- nase; mTORC1, mammalian target of rapamycin complex 1; NMDA, N-methyl-D-aspartate; NO, nitric oxide; Nrf2, nuclear factor (erythroid 2-derived)-like 2; PFC, prefrontal cortex; ROS, reactive oxygen species; SAL, salience network; Wnt, wingless-related integration site.

Table 1. Some newer antidepressants

\begin{tabular}{|c|c|c|}
\hline Vortioxetine & $\begin{array}{l}\text { 5HT3A, 5HT7, 5HT1D, } \beta-1 \text { receptor } \\
\text { antagonist } \\
\text { 5HT1A agonist } \\
\text { 5HT1B partial agonist } \\
\text { Metabolized by CYP450 2B6, 2D6, 2C8, 9, } \\
\text { 19, 3A4/5 }\end{array}$ & $\begin{array}{l}\text { Generally superior to placebo } \\
\text { Mixed results in comparisons to duloxetine } \\
\text { Inferior to fluoxetine for response, similar for remission in } 5 \\
\text { randomized controlled trials } \\
\text { Similar to venlafaxine in } 1 \text { study } \\
\text { No difference from serotonin-norepinephrine reuptake inhibitors, } \\
\text { but quality of evidence "very low" in a Cochrane Review } \\
\text { Multiple drug interactions possible }\end{array}$ \\
\hline Vilazodone & SSRI and 5HT1A partial agonist & Equivalent to 2 other antidepressants in direct comparisons \\
\hline L-milnacepran & SNRI in an extended-release formulation & $\begin{array}{l}\text { No direct comparisons to other antidepressants } \\
\text { Approved for fibromyalgia }\end{array}$ \\
\hline
\end{tabular}


specific questions where sufficient data existed [42]. The medications studied included bupropion, citalopram, desvenlafaxine, duloxetine, escitalopram, fluoxetine, fluvoxamine, mirtazapine, nefazodone, paroxetine, sertraline, trazodone, and venlafaxine. Overall, $63 \%$ of the patients responded during 6-12 weeks of acute treatment, and 47\% achieved remission. In direct and indirect comparisons, there were no clinically meaningful differences between any of the antidepressants in effectiveness, efficacy, or quality of life in acute or maintenance treatment. Mirtazepine appeared to have a somewhat faster onset of action than citalopram, fluoxetine, paroxetine, and sertraline, although this result could have been attributable to the immediate sedative effect of mirtazapine, and the finding could not be extrapolated to other medications. There was no evidence of meaningful differences in outcome in the treatment of specific subgroups defined by comorbidity, demographic factors, or symptoms such as anxiety, psychomotor changes, melancholia, or pain. There were no differences between medications in the overall risk of adverse effects, although specific adverse effects differed (e.g., more nausea with venlafaxine than with SSRI, more frequent discontinuation syndromes with paroxetine and venlafaxine, and less sexual dysfunction with bupropion).

A more recent systematic review and network metaanalysis of 522 published and unpublished double-blind, RCT (median duration 8 weeks) of adults with MDD conducted between 1979 and 2016 referenced above included studies of agomelatine, amitriptyline, bupropion, citalopram, clomipramine, desvenlafaxine, duloxetine, escitalopram, fluoxetine, fluvoxamine, levomilnacipran, milnacipran, mirtazapine, nefazodone, paroxetine, reboxetine, sertraline, trazodone, venlafaxine, vilazodone, and vortioxetine [4]. There were no meaningful differences in outcome between 474 studies that used doses within the approved range and studies that used doses outside of that range. Considering all of the data, the authors concluded that there were fewer differences between antidepressants than in a previous meta-analysis. They also noted that only aggregate data were analyzed, and most studies excluded more complicated or severely ill patients, limiting any inferences about which medication might be preferable for a given patient in actual practice. Because all treatment comparisons were for initial treatment, no data were available about response after failure of the first antidepressant. An editorial added that analysis of average data in groups of patients does not take into account the heterogeneity of responses within depressed individuals, limiting information about which antidepressants might be preferable for a particular patient [43]. Further limitations of this meta-analysis noted in a separate commentary included a moderate to high risk of bias in $82 \%$ of the studies, industry funding or no report of funding in the majority of studies, and a lack of generalizability beyond 8 weeks in a structured trial [6]. All that the current research can tell us, then, is that in the acute treatment of MDD there is no reason to choose one antidepressant over another for symptom improvement. Since the primary outcome measure in clinical trials is symptom reduction, much less information is available about improvement in functioning.

\section{What about Ketamine?}

Initial interest in ketamine was based on the putative role of NMDA receptor antagonism in response to antidepressants. However, as noted earlier, ketamine has a number of other actions, including antagonism of nicotinic and muscarinic cholinergic receptors [23], inhibition of GSK3 $\beta$ [24], increased release of norepinephrine and dopamine in the bed nucleus of the stria terminalis [44], and binding to $\mu$-opioid receptors [30], among others. In subanesthetic doses, intravenous ketamine has been found to be rapidly effective for symptoms of treatment-resistant unipolar and possibly bipolar depression, and acute suicidal ideation [45-47], with other applications having a much smaller evidence base [48]. A single intravenous dose of ketamine as monotherapy for MDD produces a rapid antidepressant effect that peaks within $24 \mathrm{~h}$, with an overall OR of 7.55 in controlled studies [49]. A review of 12 studies in unipolar depression and 7 in bipolar depression found an overall response rate of $61 \%$ at $24 \mathrm{~h}$, with ketamine always being superior to placebo for symptom reduction and for response [47]. However, there has only been one dose-finding study [50], and the optimal dose for an individual patient remains to be determined [8]. A single intravenous dose of ketamine was superior to intravenous midazolam in reducing a rating of suicidality over $24 \mathrm{~h}$ (effect size, 0.75 ), but improvement on the Hamilton Depression Rating Scale was not significantly superior to that on benzodiazepine and patients had a lifetime history of taking only 4 antidepressants in 2 antidepressant classes [51]. The reduction of suicidality ratings was within the range reported for antidepressants in depressed, suicidal patients. There are a few reports of use of oral and intranasal formulations of ketamine for treatment-resistant depression [30, 52], but there is little in the way of controlled research and there has been no careful investigation of the degree to which 
rapid response is a function of the route of administration. Ketamine is said to be particularly useful for refractory depression, but treatment resistance is usually defined as failure to respond to 1 or 2 antidepressants during the current episode. Careful controlled research has not been conducted in depression with multiple failed trials of antidepressants with augmentation and electroconvulsive therapy (ECT) or with comorbid disorders.

Common adverse effects of ketamine include dizziness, neurotoxicity, cognitive dysfunction, blurred vision, psychosis, dissociation, restlessness, headache, nausea, vomiting, and cardiovascular and urological dysfunction $[47,53,54]$. Adverse effects tend to be brief in acute treatment with low doses, but they are more problematic at higher doses or over longer periods of administration [53]. Although acute treatment with ketamine may be neuroprotective, a more prolonged exposure may predispose to neurotoxicity and drug dependence [30]; other long-term adverse effects are not known $[45,47]$.

In a 2015 systematic review and meta-analysis, an overall significant OR of continued response 1 week after a single infusion of ketamine was 4.72 for unipolar depression but it was not significant for bipolar depression; however, the results for unipolar depression were only significant in one third of the studies that reported 1-week follow-up data [49]. Symptom remission was significant a day and a week after infusion for unipolar depression but just on the first day for bipolar depression [49]. In the few reports in which infusions have been continued openly for a few weeks, the relapse rate within 1 month after discontinuation of ketamine infusion has been 55-89\% [30].

An approach to prolonging the antidepressant effect of ketamine was tested in an open-label study of $16 \mathrm{MDD}$ patients (mean age 42.7 years) with a mean duration of the current episode of 47 months who had failed an average of 2.64 antidepressant trials; 6 patients $(37.5 \%)$ had a history of receiving ECT in the past, but their response was not noted [55]. All patients received 2 intravenous doses of ketamine a week for 2 weeks and started cognitive behavior therapy (CBT) after the first ketamine infusion. CBT was continued for 8 weeks following discontinuation of ketamine. Response $(\geq 50 \%$ reduction in Mongtgomery Asberg Rating Scale [MADRS] score) occurred in 8 patients and remission (MADRS score $\leq 9)$ in 7. Among responders and remitters, the median time to relapse was 12 weeks, which was longer than in studies of ketamine alone; most relapses occurred after discontinuation of CBT. The conclusion that CBT prolonged the response to ketamine is limited by the small sample, the open-label design, the lack of a control group, the absence of a direct comparison to ketamine without CBT, and open adjustment of concomitant medications in $25 \%$ of the patients. In the comparison of ketamine and midazolam discussed earlier [51], open-label follow-up found a continued reduction of suicidality rating scale scores over 6 weeks, but during this time antidepressants and other medications were adjusted openly.

In view of the inevitable decay of the response to ketamine [48] and its possible benefit in at least somewhat refractory depression, maintenance therapy would seem to be an important consideration, but no reliable longterm data are available [30]. The lack of guidelines about therapeutic monitoring of maintenance ketamine treatment for depression further complicates the expanding use of this treatment [30]. Nevertheless, a number of psychiatrists routinely administer chronic ketamine dosing for depression. Some psychiatrists administer intravenous ketamine without an anesthesiologist, and even more remarkably some anesthesiologists provide ketamine for depression without a psychiatrist [48]. Some clinicians use ketamine formulations that have little to no empirical support for acute, let alone chronic, use. The "cavalier nature" of this practice provoked alarm in some experts regarding "the rapid proliferation of off-label ketamine administration in the absence of evidence of lasting therapeutic benefit or safety with long-term administration" [p. 686 in 30].

One conceivable use of ketamine based on the availability of short-term data would be as an adjunct to ECT. An uncontrolled report has emerged of a synergistic effect between S-ketamine and ECT [56]. However, even if it prolongs seizure duration, ketamine has generally not been found to be effective in augmenting ECT $[46,49,57]$, possibly because the rate of response to ECT is so high that it is difficult to augment it. In 1 or 2 doses, ketamine might be an appropriate choice for severely depressed and acutely suicidal patients while a more definitive rapidly acting treatment such as ECT is being arranged. However, no reports of this application have yet emerged.

\section{Ketamine Derivatives and Related Drugs}

The S-enantiomer of ketamine (S-ketamine or esketamine) has a 3-4 times greater affinity than ketamine for the NMDA receptor [58]. In an industry-sponsored double-blind study of 30 patients (mean age 43 years) with treatment-resistant depression, an intravenous infusion of esketamine was superior to placebo in reducing depression rating scale scores beginning at $2 \mathrm{~h}$, with an ef- 
fect size of 1.54-1.70 [58]. No patients had a response ( $\geq 50 \%$ symptom improvement) to placebo, while two thirds had a response to esketamine for 3 days after a single dose. A subset of patients who received 4 more openlabel infusions spaced 3-4 days apart continued to respond. In a phase 2, industry-sponsored study of 67 patients with treatment-resistant depression (64\% of whom had not responded to a single antidepressant during the current episode) [59] intranasal esketamine added to ongoing antidepressant therapy was significantly superior to placebo in reducing depressive symptoms during a 2 -week double-blind phase. Subsequently, 5 weeks of open-label treatment twice a week followed by open administration once a week and then once every other week resulted in increasing improvement that was maintained at 8 weeks of follow-up without further treatment. The manufacturer is now conducting 3 studies of twice weekly intranasal esketamine added to "standard of care" antidepressants in MDD with acute suicidal ideation. One study consists of a 4-week DBPC study in adults (NCT03097133). A second adult study (NCT03039192) is a 4 -week DBPC trial followed by a 65 -day follow-up. A pediatric study (NCT03185819) involves a 4-week DBPC phase, an 8-week posttreatment phase, and a 6-month follow-up. No data are available from any of these studies.

Based on the short-term success of ketamine and the possible benefit of intranasal esketamine, other glutamate receptor modulators have been studied to some extent in small studies as monotherapy or an adjunct to antidepressants. Examples include noncompetitive NMDA receptor antagonists (memantine, dextromethorphan/quinidine, dextromethorphan/bupropion, and lanicemine), NR2B subunit-specific NMDA receptor antagonists (traxoprodil, MK-0657), NMDA receptor glycine site partial agonists (D-cycloserine, rapastinel), and metabotropic glutamate receptor (mGluR) antagonists (basimglurant, declogurant) $[8,49,50,60-62]$. Memantine, MK0657 , and rapastinel have not convincingly outperformed placebo, while the other preparations are still under study [49]. There are insufficient data (and no long-term data) to assess even a potential acute benefit of any of these medications.

\section{The Potential Pipeline}

The development of other novel antidepressants has followed the same path as glutamate receptor modulators, neurotransmitter reuptake inhibitors, and receptor antagonists. New compounds are modeled on one or an- other presumed therapeutic action of a known antidepressant or the hypothetical role of a specific target in the pathophysiology of depression, with the hope that the new molecule will result in a better clinical effect or, as a secondary outcome, fewer adverse effects. Despite emerging data on the potential role of intracellular signals, gene expression, and network connectivity, many of these targets are still neurotransmitters and receptors. A few examples of such directions in antidepressant development are summarized in Table $2[8,23,63,64]$.

Some of these compounds may be novel in that medications with similar structures or receptor actions are not yet on the market, but the process of drug development is not. New neurotransmitter reuptake inhibitors based on the presumed therapeutic action of first- and second-generation antidepressants have not proven to be superior to previous generations. Similarly, there are no data suggesting that repeating the same approach but with a new receptor target - or any other discrete target - is likely to produce better results. Even if apparently novel findings emerged using traditional clinical trials, a number of factors would limit the applicability of such findings to reallife clinical practice.

One issue affecting most product development in psychiatry is that the high costs involved dictate that industry-sponsored efficacy and safety trials of new medications are designed to obtain regulatory approval rather than answer open questions such as the optimal treatment for specific patients. For the same reason, such studies enroll relatively homogeneous groups of subjects who are most likely to respond to a single intervention. Features that reduce the chance of a positive result, such as: chronicity; severity; resistance to multiple treatments; psychiatric, substance use, and medical comorbidity; psychosis; character pathology; bipolarity; and other complicating factors, are exclusion criteria. Unlike most clinical trials, manufacturer-sponsored studies of esketamine allow suicidality, but these studies exclude everything else except otherwise uncomplicated MDD. Exclusion of features that are common in depressed patients seen in everyday psychiatric practice eliminate most depressed psychiatric outpatients from the vast majority of antidepressant clinical trials, limiting implications for most cases of depression in specialty practice [65]. Similarly, exclusion of active medical comorbidity argues against the contention that depressed patients in registration trials resemble patients in primary care practice.

Even relatively uncomplicated MDD is characterized by considerable clinical heterogeneity in terms of history, specific symptom clusters, functioning, and treatment re- 
Table 2. Some recent receptor targets for antidepressant development

\begin{tabular}{lll}
\hline Target receptor & $\begin{array}{l}\text { Medication } \\
\text { examples }\end{array}$ & Comment \\
\hline Muscarinic cholinergic & Scopolamine & $\begin{array}{l}\text { This is based on observations that receptors increase the glutamate release and the role } \\
\text { of acetylcholine in mediating punishment. }\end{array}$ \\
\hline Opioid receptors & $\begin{array}{l}\text { Buprenorphine } \\
\text { Samidorphan }\end{array}$ & $\begin{array}{l}\text { Elevated expression of dynorphin, acting on KOR, may promote the neurobiology } \\
\text { of depression; KOR antagonists may have antidepressant effects but are not useful } \\
\text { clinically. } \\
\text { MOR agonists improve depression. } \\
\text { Buprenorphine has been used as an antidepressant. } \\
\text { It is illegal in the USA to use opioids as a primary treatment for depression. }\end{array}$ \\
\hline NK1 & $\begin{array}{l}\text { Casopitant } \\
\text { Orvepitant }\end{array}$ & $\begin{array}{l}\text { Substance P, a neurotransmitter of pain, acts on the NK-1 receptor. } \\
\text { occupancy. }\end{array}$ \\
\hline Vasopressin V(1b) & Nelivaptan & $\begin{array}{l}\text { Vasopressin functions as a stress hormone and may be hyperactive in depression. } \\
\text { V(1b) antagonist had mixed results in initial studies. }\end{array}$ \\
\hline
\end{tabular}

NK1, neurokinin-1; KOR, $\kappa$-opioid receptor; MOR, $\mu$-opioid receptor; CNS, central nervous system.

sponse and course [66]. Depression has an early onset in some patients and a later onset in others. Some patients have frequent recurrences and others do not. Some cases are familial, while others are sporadic. Some have a past history of trauma or loss, while others have apparently normal childhoods. In some patients, depression intrudes into the personality; other patients maintain the integrity of their personalities despite severe suffering. Some depressed patients develop impairment of cognition or reasoning, while others do not. These and other dimensions of illness, not to mention more obvious subtypes such as severe, refractory, or psychotic depression, may be associated with differing dimensions of neurobiology that predict preferential responses to one treatment and not another. Even trials in which aggregate data do not reveal an overall superiority to placebo or another active treatment therefore might provide useful data about subgroups that do respond preferentially to the experimental drug. However, unlike studies of other new medical therapies such as cancer chemotherapy, the number of subjects in antidepressant trials is generally too low to perform a meaningful subgroup analysis if this were a priority.

In many areas of clinical medicine, recognition of the interaction between elements of pathophysiology and of suboptimal results with monotherapy have moved practice guidelines for pharmacotherapy of disorders as straightforward as essential hypertension toward a low threshold for combination therapies, especially if remis- sion is incomplete $[67,68]$. Antidepressant-antipsychotic drug combination therapy has been studied in psychotic depression [69], usually in small investigator-initiated trials, and its effectiveness appears to be a function of complex neurobiological interactions rather than simple additive antipsychotic and antidepressant actions [70]. In contrast, most clinical trials of new antidepressants in nonpsychotic depression, which are largely industry sponsored, examine a single medication. The failure of remission rates to increase much beyond $30-40 \%$ with initial antidepressant monotherapy in MDD despite the advent of new medications [71, 72] may well reflect the need for combinations of treatments that have to be individualized based on specific dimensions of illness for maximum benefit, just as in other medical disorders. One important combination that has been shown to improve outcomes but has not been considered in clinical trials of new antidepressants is the combination of medications and psychotherapy [73].

Another issue in the current approach to antidepressant development concerns the outcome measures used in clinical trials. By consensus, response is defined as a $50 \%$ improvement in depression rating scale scores, and remission is defined as a decrease to the equivalent of 7 or less on the Hamilton Depression Rating Scale or a MADRS score of $9-10$ or less $[55,74]$. Considering initial scores in the range of 20-30, a patient in remission would be one third as depressed after treatment. Indeed, most "remit- 
ted" patients retain some level of symptomatology at the end of an antidepressant trial. Using a definition of remission in some longitudinal research as at least 1 episodefree year, the remission rate in MDD increases from 35$40 \%$ to $50 \%$ [75]. Since the definition of an episode requires a minimum number of symptoms, it is possible in this context to have subsyndromal depression and still technically be in remission, even though residual symptoms would convey an increased risk of relapse [76]. Furthermore, none of these definitions includes role and occupational functioning, which may be impaired after all symptoms have resolved and which indicate continued illness [77]. Some antidepressant trials include quality-oflife measures that are not primary outcomes, and without following patients prior to the onset of depression it is difficult to determine whether the quality of life after treatment returns to its premorbid level. Measures of psychosocial function are less frequent, and it is similarly difficult to know what score on a functional measure should be considered remitted. Yet since continued psychosocial dysfunction not only impairs quality of life but also increases the risk of syndromal recurrence, clinicians cannot assume that remission in a clinical trial actually corresponds to true recovery. Absence of complete recovery from the initial episode, with failure to reset the pathophysiology and psychology of depression, may lead to compensatory changes to which the antidepressant no longer responds, or to rebound of that pathophysiology when the antidepressant is withdrawn, accounting for reports of increasing relapse rates with prolonged antidepressant maintenance and refractoriness to an antidepressant that was discontinued after the patient has responded [78].

\section{How to Develop Truly Innovative Antidepressants}

The search for the next discrete antidepressant target may produce medications that are as effective as existing ones and that some patients may tolerate better than some others. However, given the heterogeneity of depression and the lack of data about depression complicated by chronicity, comorbidity, substance use, suicidality, or other factors commonly encountered in clinical practice, traditional drug discovery methods might be reconsidered. The first step would be to increase the number and heterogeneity of subjects in clinical trials in order to assess the impact of treatment on clinically meaningful subtypes. The primary obstacle to implementing this recommendation is the expense of conducting clinical trials that are larger or more diverse than is necessary to lead directly to regulatory approval or extension of approved indications. In the long run, determining which patients are most likely to respond to which treatments or combinations of treatments could enhance the likelihood of finding marketable niches for new products, but the return on investment would not be rapid and might be difficult to predict. There has been some independent federal funding of practical clinical trials in psychiatry comparing aggregate outcomes with different medications, such as STAR*D (National Institute of Mental Health) [79], VAST-D (US Department of Veterans Affairs) [72], and the EUFEST (European Union) [80], but the development of new psychotropic medications has generally been deferred to industry. As an alternative, if antitrust laws permitted it, manufacturers might collaborate to conduct large-scale clinical trials examining the specific applications of new medications with different actions on depressive subtypes, perhaps sharing in jointly developed products. This kind of collaboration is not unheard of; for example, General Motors and Ford recently collaborated on the development of a new transmission shared by vehicles of both manufacturers.

If larger, more heterogeneous populations that more closely resemble patients seen in practice can be enrolled into clinical trials, the next step would be to ensure the inclusion of a broader range of outcome measures, including robust markers of functioning and cognition. This would require clearly established norms on measures of functioning and studies that are sufficiently powered to assess these outcomes. If remission is defined as the absence of residual symptoms and a return to premorbid functioning and quality of life, the remission rate with monotherapy would be expected to be lower than the already low rate using a relative reduction of symptom rating scale scores. It would then be possible to construct clinical trials that assess the relative effectiveness of different medication combinations in achieving true remission. Such studies could be encouraged by regulatory requirements such as those that reward studies in children and adolescents following the initial approval of antidepressants in adults.

It seems self-evident that if any medication is better tolerated patients are more likely to continue taking it, and it is more likely to work, whereas adverse effects lead almost half of depressed patients to discontinue antidepressants [81]. The development of new antidepressants takes adverse effects into account as secondary measures but generally does not integrate such measures into the overall formulation of the product. This is particularly 
true for withdrawal and rebound syndromes, which may be associated with antidepressant tolerance and discontinuation-induced refractoriness [73]. Newer available antidepressants were introduced with the expectation that they would be better tolerated, but further experience demonstrated at most modest differences in tolerability between previous-generation and newer antidepressants, especially considering adverse effects that manifest only after prolonged treatment [81]. The development of new medications, especially if they are to be used in combination with other treatments, should include approaches to minimizing adverse effects, especially on mood [81], as well as discontinuation syndromes. Adverse effects that seem minimal in clinical trials of otherwise healthy patients with MDD may be intolerable in those with comorbid and chronic disorders.

New antidepressants may be more or less equivalent in overall outcomes, but they may have differential effects on different domains of depressive disorders. Defining specific dimensions of depressive disorders would facilitate studying the relative benefit of one or a combination of medications in different depressive subtypes. The Re- search Domain Criteria are already facilitating the identification of discrete features that are associated with discrete physiologic and psychological variables [82, 83]. In contrast to categorical diagnoses, such dimensions are more clearly linked to neurobiological and genetic factors that are more likely to be medication targets. By definition, the same is true of endophenotypes such as anhedonia, cognitive control, neuroticism, and hypothalamicpituitary-adrenal axis dysfunction [84]. New treatments can be designed that act on specific elements of neurobiology linked to such dimensions, permitting combinations of medications that act on the specific assortments of dimensions that characterize individual depressive subtypes. This would be the beginning of truly scientific personalized antidepressant therapy.

\section{Disclosure Statement}

Dr. Dubovsky has received research support from Janssen, Otsuka, Sumitomo, Neurocrine, the Tower Foundation, the Wendt Foundation, the Oshei Foundation, and the Patrick Lee Foundation. The author has no other conflicts of interests to disclose.

\section{References}

-1 Gibbons RD, Hur K, Brown CH, Davis JM, Mann JJ: Benefits from antidepressants: synthesis of 6-week patient-level outcomes from double-blind, placebo-controlled randomized trials of fluoxetine and venlafaxine. Arch Gen Psychiatry 2012;69:572-579.

-2 Davey CG, Chanen AM: The unfulfilled promise of the antidepressant medications. Med J Aust 2016;204:348-350.

3 Wang SM, Han C, Lee SJ, Jun TY, Patkar AA, Masand PS, Pae CU: Efficacy of antidepressants: bias in randomized clinical trials and related issues. Expert Rev Clin Pharmacol 2018;11:15-25.

-4 Cipriani A, Furukawa TA, Salanti G, Chaimani A, Atkinson LZ, Ogawa Y, Leucht S, Ruhe HG, Turner EH, Higgins JPT, Egger M, Takeshima N, Hayasaka Y, Imai H, Shinohara K, Tajika A, Aloannidis JP: Comparative efficacy and acceptability of 21 antidepressant drugs for the acute treatment of adults with major depressive disorder: a systematic review and network meta-analysis. Lancet 2018 , DOI: 10.1016/S0140-6736(17)32802-7.

$\checkmark 5$ Furukawa TA, Cipriani A, Atkinson LZ, Leucht S, Ogawa Y, Takeshima N, Hayasaka Y, Chaimani A, Salanti G: Placebo response rates in antidepressant trials: a systematic review of published and unpublished doubleblind randomised studies. Lancet Psychiatry 2016;3:1059-1066.
6 McCormack J, Korownyk C: Effectiveness of antidepressants: lots of useful data but many important questions remain. BMJ 2018, p 360.

7 Musliner KL, Munk-Olsen T, Laursen TM, Eaton WW, Zandi PP, Mortensen PB: Heterogeneity in 10-year course trajectories of moderate to severe depressive disorder: a Danish National Register-based study. JAMA Psychiatry 2016;73:346-353.

$\checkmark 8$ Ionescu DF, Papakostas GL: Experimental medication treatment approaches for depression. Transl Psychiatry 2017;7:e1068.

$\checkmark 9$ Schildkraut J: Norepinephrine metabolism and drugs used in the affective disorders: a possible mechanism of action. Am J Psychiatry 1967;124:600-608.

$>10$ Diaz SL, Doly S, Narboux-Neme N, Fernandez S, Mazot P, Banas SM, Boutourlinsky K, Moutkine I, Belmer A, Roumier A, Maroteaux L: 5-HT(2B) receptors are required for serotonin-selective antidepressant actions. Mol Psychiatry 2012;17:154-163.

11 Zhang F, Shao J, Tian J, Zhong Y, Ye L, Meng X, Liu Q, Wang HR: Antidepressant-like effects of LPM580253, a triple reuptake inhibitor. Sci Rep 2016;6:24333.

12 Korte SM, Prins J, Krajnc AM, Hendriksen H, Oosting RS, Westphal KG, Korte-Bouws GA, Olivier B: The many different faces of major depression: it is time for personalized medicine. Eur J Pharmacol 2015;753:88-104.
13 Evans JW, Szcepanik J, Brutsche NE, Park LT, Nugent AC, Zarate CA: Default mode connectivity in major depressive disorder measured up to 10 days after ketamine administration. Biol Psychiatry 2018;38:243-246.

14 Chamba G, Lemoine P, Flachaire E, Ferry N, Quincy C, Sassard J, Ferber C, Mocaer E, Kamoun A, Renaud B: Increased serotonin platelet uptake after tianeptine administration in depressed patients. Biol Psychiatry 1991;30:609-617.

15 Nelson JC, Portera L, leon AC: Are there differences in the symptoms that respond to a selective serotonin or norepinephrine reuptake inhibitor? Biol Psychiatry 2005;57:15351542.

16 Freemantle N, Anderson IM, Young P: Predictive value of pharmacological activity for the relative efficacy of antidepressant drugs: meta-regression analysis. $\mathrm{Br} \mathrm{J}$ Psychiatry 2000;177:292-302.

17 Di Benedetto B, Rupprecht R, Czeh B: Talking to the synapse: how antidepressants can target glial cells to reshape brain circuits. Curr Drug Targets 2013;14:1329-1335.

-18 Posner J, Hellerstein DJ, Gat I, Mechling A, Klahr K, Wang Z, McGrath PJ, Stewart JW, Peterson BS: Antidepressants normalize the default mode network in patients with dysthymia. JAMA Psychiatry 2013;70:373-382. 
$>19$ Launay JM, Mouillet-Richard S, Baudry A, Pietri M, Kellermann O: Raphe-mediated signals control the hippocampal response to SRI antidepressants via miR-16. Transl Psychiatry 2011;1:e56.

20 Schroeder M, Hillemacher T, Bleich S, Frieling $\mathrm{H}$ : The epigenetic code in depression: implications for treatment. Clin Pharmacol Ther 2011;91:310-314.

21 Voleti B, Duman RS: The roles of neurotrophic factor and Wnt signaling in depression. Clin Pharmacol Ther 2012;91:333-338.

-22 Yao W, Zhang JC, Ishima T, Ren Q, Yang CC, Dong C, Ma M, Saito A, Honda T, Hashimoto $\mathrm{K}$ : Antidepressant effects of TBE-31 and MCE-1, the novel Nrf2 activators, in an inflammation model of depression. Eur J Pharmacol 2016;793:21-27.

23 Wohleb ES, Gerhard D, Thomas A, Duman RS: Molecular and cellular mechanisms of rapid-acting antidepressants ketamine and scopolamine. Curr Neuropharmacol 2017;15: $11-20$.

24 Costemale-Lacoste JF, Guiloux JP, Gaillard R: The role of GSK-3 in treatment-resistant depression and links with the pharmacological effects of lithium and ketamine: a review of the literature. Encephale 2016;42:156-164.

-25 Guo F, Zhang B, Fu Z, Ma YT, Gao Y, Shen F, Huang C-C, Li Y: The rapid antidepressant and anxiolytic-like effects of YY-21 involve enhancement of excitatory synaptic transmission via activation of $\mathrm{mTOR}$ signaling in the mPFC. Eur Neuropsychopharmacol 2016;26: 1087-1098.

-26 Vai B, Bulgarelli C, Godlewska BR, Cowen PJ, Benedetti F, Harmer CJ: Fronto-limbic effective connectivity as possible predictor of antidepressant response to SSRI administration. Eur Neuropsychopharmacol 2016;26:20002010.

-27 Zanos P, Moaddel R, Morris PJ, Georgiou P, Fischell J, Elmer GI, Alkodon M, Yuan P, Pribut HJ, Singh NS, Dossou KS, Fang Y, Huang XB, Mayo CL, Wainer IW, Albuquerque EX, Thompson SM, Thomas CJ, Zarate CA, Gould TD: NMDAR inhibition-independent antidepressant actions of ketamine metabolites. Nature 2016;533:481-486.

28 Eliwa H, Belzung C, Surget A: Adult hippocampal neurogenesis: is it the alpha and omega of antidepressant action? Biochem Pharmacol 2017;141:86-99.

-29 Castren E, Kojima M: Brain-derived neurotrophic factor in mood disorders and antidepressant treatment. Neurobiol Dis 2017;97: 119-126.

-30 Newport DJ, Schatzberg AF, Nemeroff CB: Whither ketamine as an antidepressant: panacea or toxin? Depress Anxiety 2016;33:685688.
31 Griffiths CEM, Fava M, Miller AH, Russell J, Ball SG, Xu W, Acharya N, Rapaport MH: Impact of ixekizumab treatment on depressive symptoms and systemic inflammation in patients with moderate-to-severe-psoriasis: an integrated analysis of three phase 3 clinical studies. Psychother Psychosom 2017;86:260 267.

-32 Block TS, Kushner H, Kalin N, Nelson C, Belanoff J, Schatzberg AF: Combined analysis of mifepristone for psychotic depression: plasma levels associated with clinical response. Biol Psychiatry 2018, DOI: 10.1016/j.biopsych.2018.01.008.

33 Dubovsky SL: Pharmacokinetic evaluation of vortioxetine for the treatment of major depressive disorder. Expert Opin Drug Metab Toxicol 2014;10:759-766.

34 Edwards J, Sperry V, Adams MH, Gallipoli S, Thorn MD, Longstreth J, Boinpally R: Vilazodone lacks proarrhythmogenic potential in healthy participants: a thorough ECG study. Int J Clin Pharmacol Ther 2013;51:456-465.

35 Orsolini L, Tomasetti C, Valchera A, Iasevoli F, Buonaguro EF, Fornaro M, Fiengo ALC, Martinotti G, Vellante F, Matarazzo I, Vecchiotti R, Perna G, Nicola MD, Carano A, Bartolomeis A, Giannantonio MD, Berardis $D$ : Current and future perspectives on the major depressive disorder: focus on the new multimodal antidepressant vortioxetine. CNS Neurol Disord Drug Targets 2017;16:62-95.

-36 Montgomery SA, Gommoll CP, Chen CC, Greenberg WM: Efficacy of levonilnacipran extended-release in major depressive disorder: pooled analysis of 5 double-blind, placebo-controlled trials. CNS Spectr 2015;20: 148-156.

37 Li G, Wang X, Ma D: Vortioxetine versus duloxetine in the treatment of patients with major depressive disorder: a meta-analysis of randomized controlled trials. Clin Drug Investig 2017;36:509-517.

38 Saraceni MM, Venci JV, Gandhi MA: Levomilnacipran (Fetzima): a new serotonin-norepinephrine reuptake inhibitor for the treatment of major depressive disorder. J Pharm Pract 2014;27:389-395.

- 39 Koesters M, Ostuzzi G, Guaiana G, Breilmann J, Barbui C: Vortioxetine for depression in adults. Cochrane Database Syst Rev 2017;7: CD011520.

40 Salagre E, Sole B, Tomioka Y, Fernandes BS, Hidalgo-Mazzei D, Garriga M, Jimenez E, Sanchez-Moreno J, Vieta E, Grande I: Treatment of neurocognitive symptoms in unipolar depression: a systematic review and future perspectives. J Affect Disord 2017;221:205221.

41 Papp M, Gruca P, Lason-Tyburkiewicz M, Willner P: Antidepressant, anxiolytic and procognitive effects of subacute and chronic ketamine in the chronic mild stress model of depression. Behav Pharmacol 2017;28:1-8.
42 Gartiehner G, Hansen RA, Morgan LC, Thaler K, Lux L, Van Noord M, Mager U, Thieda P, Gaynes BN, Wilkins T, Strobelberger M, Lloyd S, Reichenpfader U, Lohr KN: Comparative benefits and harms of second-generation antidepressants for treating major depressive disorder. Ann Intern Med 2011;155: 772-785.

43 Parikh SV, Kennedy SH: More data, more answers: picking the optimal antidepressant. Lancet 2018;391:1333-1334.

44 Cadeddu R, Jadzic D, Carboni E: Ketamine modulates catecholamine transmission in the bed nucleus of stria terminalis: the possible role of this region in the antidepressant effects of ketamine. Eur Neuropsychopharmacol 2016;26:1678-1682.

-45 Schwartz JB, Murrough JW, Iosifescu DV: Ketamine for treatment-resistant depression: recent developments and clinical applications. Evid Based Ment Health 2016;19:3538.

46 Bobo WV, Vande Voort JL, Croarkin PE, Leung JG, Tye SJ, Frye MA: Ketamine for treatment resistant unipolar and bipolar major depression: critical review and implications for clinical practice. Depress Anxiety 2016;33:698-710.

47 Kraus C, Rabl U, Vanicek T, Carlberg L, Popovic A, Spies M, Bartova L, Gryglewski G, Papageorgiou K, Lanzenberger R, Willeit M, Winkler D, Rybakowski JK, Kasper S: Administration of ketamine for unipolar and bipolar depression. Int J Psychiatry Clin Pract 2017; 21:2-12.

48 Nemeroff CB: Ketamine: quo vadis? Am J Psychiatry 2018;174:297-299.

49 Newport DJ, Carpenter LL, McDonald WM, Potash JB, Tohen M, Nemeroff CB: Ketamine and other NMDA antagonists: early clinical trials and possible mechanisms in depression. Am J Psychiatry 2015;172:950-966.

50 Lener MS, Kadriu B, Zarate CA: Ketamine and beyond: investigations into the potential of glutaminergic agents to treat depression. Drugs 2017;77:381-401.

51 Grunebaum MF, Galfalvy HC, Choo T-H, Keilp JG, Moitra VK, Parris MS, Marver JE, Burke AK, Milak MS, Sublette ME, Oquendo MA, Mann JJ: Ketamine for rapid reduction of suicidal thoughts in major depression: a midazolam-controlled randomized clinical trial. Am J Psychiatry 2018;175:327-335.

52 Swiatek KM, Jordan K, Coffman J: New use for an old drug: oral ketamine for treatmentresistant depression. BMJ Case Rep 2016, DOI: $10.1136 / \mathrm{bcr}-2016-216088$

53 Zhu W, Ding Z, Zhang Y, Shi J, Hashimoto K, $\mathrm{Lu}$ L: Risks associated with misuse of ketamine as a rapid-acting antidepressant. Neurosci Bull 2016;32:557-564.

54 Liu Y, Lin D, Wu B, Zhou W: Ketamine abuse potential and use disorder. Brain Res Bull 2016;126:68-73. 
-55 Wilkinson ST, Wright D, Fasula MK, Fenton L, Griepp M, Ostroff R, Sanacora G: Cognitive behavior therapy may sustain antidepressant effects of intravenous ketamine in treatmentresistant depression. Psychother Psychosom 2017;86:162-167.

-56 Kallmunzer B, Volbers B, Karthaus A, Tektas OY, Kornhuber J, Muller HH: Treatment escalation in patients not responding to pharmacotherapy, psychotherapy, and electroconvulsive therapy: experiences from a novel regimen using intravenous S-ketamine as add-on therapy in treatment resistant depression. J Neural Transm (Vienna) 2017;123: 549-552.

57 McGirr A, Berlim MT, Bond DJ, Chan PY, Yatham LN, Lam RW: Adjunctive ketamine in electroconvulsive therapy: updated systematic review and meta-analysis. Br J Psychiatry 2017;210:403-407.

58 Singh JB, Fedchin M, Daly E, Xi L, Melman C De Bruecker G, Tadic A, Sienaert P, Wiegand F, Manji HA, Drevets WC, Van Nueten L: Treatment-resistant depression: a doublebline, double-randomization, placebo-controlled study. Biol Psychiatry 2016;80:424431.

59 Daly EJ, Singh JB, Fedgchin M, Cooper K, Lim P, Shelton RC, Thase ME, Winokur A, Van Nueten L, Manji HA, Drevets WC: Efficacy and safety of intranasal esketamine adjunctive to oral antidepressant therapy in treatmentresistant depression: a randomized clinical trial. JAMA Psychiatry 2018;75:139-148.

-60 Jaso BA, Niciu MJ, Iadarola ND, Lally N, Richards EM, Park MH, Ballard ED, Nugent AC, Machado-Vieira R, Zarate CA: Therapeutic modulation of glutamate receptors in major depressive disorder. Curr Neuropharmacol 2017;15:57-70.

-61 Salardini E, Zeinoddini A, Mohammadinejad P, Khodaie-Ardakani MR, Zahrei N, Zeinoddini A, Akhondzadeh S: Riluzole combination therapy for moderate-to-severe major depressive disorder: a randomized, doubleblind, placebo-controlled trial. J Psychiatr Res 2016;75:24-30.

62 Murrough JW, Wade E, Sayed S, Ahle G, Kiraly DD, Welch A, Collins KA, Soleimani L, Tosifescu DV, Charney DS: Dextromethorphan/quinidine pharmacotherapy in patients with treatment resistant depression: a proof of concept trial. J Affect Disord 2017;218:277283.

63 Carlezon WAJ, Krystal AD: Kappa-opioid antagonists for psychiatric disorders: from bench to clinical trials. Depress Anxiety 2016; 33:895-906

64 Falcon E, Browne CA, Leon RM, Fleites VC, Sweeney R, Kirby LG, Lucki I: Antidepressant effects of buprenorphine are mediated by kappa opioid receptors. Neuropsychopharmacology 2016;41:2344-2351.
65 Zimmerman ME, Chelminski I, Posternak MA: Exclusion criteria used in antidepressant efficacy trials: consistency across studies and representativeness of samples included. J Nerv Ment Dis 2004;192:87-94.

66 Dubovsky SL, Thomas M: Beyond specificity: effects of serotonin and serotonergic treatments on psychobiological dysfunction. J Psychosom Res 1995;39:429-444.

67 Mancia G, Fagard R, Narkiewicz K, Redon J, Zanchetti A, Bohm M, Christiaens T, Cifkova R, De Backer G, Dominiczak A, Galderisi M, Grobbee DE, Jaarsma T, Kirchhof P, Kjeldsen SE, Laurent S, Manolis AJ, Nilsson PM, Ruilope M, Schmieder RE, Sirnes PA, Sleight P, Viigimaa M, Waeber B, Zannad F: 2013 ESH/ESC practice guidelines for the management of arterial hypertension. Blood Press 2014;223:3-16

68 Weber MA, Schiffrin EL, White WB, Mann SA, Lindholm LH, Kenerson JG, Flack JM, Carter BL, Materson BJ, Ram CVS, Cohen DL, Cadet J-C, Jean-Charles RR, Taler S, Kountz D, Townsend R, Chalmers J, Ramirez AJ, Bakris GL, Wang J, Schutte AE, Bisognano JD, Touyz RM, Sica D, Harrap SB: Clinical practice guidelines for the management of hypertension in the community: a statement by the American Society of Hypertension and the International Society of Hypertension. J Hypertens 2014;32:3-15.

69 Andreescu C, Mulsant BH, Rothschild AJ, Flint AJ, Meyers BS, Whyte EM: Pharmacotherapy of major depression with psychotic features: what is the evidence? Psychiatr Ann 2006;36:31-38

70 Rogoz Z: Combined treatment with atypical antipsychotics and antidepressants in treatment-resistant depression: preclinical and clinical efficacy. Pharmacol Rep 2013;65: 1535-1544.

71 Mohamed S, Johnson GR, Vertrees JE, Guarino $\mathrm{PD}$, Weingart $\mathrm{K}$, Young IT, Yoon JS, Gleason TC, Kirkwood KA, Gerrity M, Marder SR, Biswas K, Hicks P, Davils LL, Chen P, Kelada A, Lawrence DD, LeGwin M, Zisook $S$ : The VA augmentation and switching treatments for improving depression outcomes (VAST-D) study: rationale and design considerations. Psychiatry Res 2015;229:760770.

72 Mohamed S, Johnson GR, Chen P, Hicks P, Davis LL, Yoon JS, Gleason TC, Vertrees JE, Weingart K, Tal I, Scrymgeour A, Lawrence DD, Planeta B, Thase ME, Huang GD, Zisook S: Effect of antidepressant switching vs. augmentation on remission among patients with major depressive disorder unresponsive to antidepressant treatment: the VAST-D randomized clinical trial. JAMA 2017;318:132145.

73 Fava GA: Time to rethink the approach to recurrent depression. Lancet Psychiatry 2018, DOI: $10.1016 /$ S2215-03661830128-7.
74 Thase ME, Mahableshwarkar AR, Dragheim M, Loft H, Vieta E: A meta-analysis of randomized, placebo-controlled trials of vortioxetine for the treatment of major depressive disorder in adults. Eur Neuropsychopharmacol 2016;26:979-993.

75 Kelly KM, Mezuk B: Predictors of remission from generalized anxiety disorder and major depressive disorder. J Affect Disord 2017;208: 467-474.

76 Judd LL, Schettler PJ, Rush AJ, Coryell W, Fiedorowicz JG, Solomon DA: A new empirical definition of major depressive episode recovery and its positive impact on future course of illness. J Clin Psychiatry 2016;77: 1065-1073.

77 Zimmerman M, McGlinchey JB, Posternak MA, Friedman M, Boerescu D, Attiullah N: Remission in depressed outpatients: more than just symptom resolution? J Psychiatr Res 2008;42:797-801

78 Fava GA: Rational use of antidepressant drugs. Psychother Psychosom 2014;83:197204

79 Olbert CM, Rasmussen A, Gala GJ, Tupler LA: Treatment outcome variation between depression symptom combinations in the STAR*D study. J Affect Disord 2016;201:1-7.

80 Landolt K, Rossler W, Ajdacic-Gross V, Derks EM, Libiger J, Kahn RS, Fleischhacker WW: Predictors of discontinuation of antipsychotic medication and subsequent outcomes in the European First Episode Schizophrenia Trial (EUFEST). Schizophr Res 2016; 172:145-151.

81 Carvalho AF, Sharma MS, Brunoni AR, Vieta E, Fava GA: The safety, tolerability and risks associated with the use of newer generation antidepressant drugs: a critical review of the literature. Psychother Psychosom 2016;85: 270-288

82 Mckay D, Tolin DF: Empirically supported psychological treatments and the Research Domain Criteria (RDoC). J Affect Disord 2017;216:78-88.

-83 Fineberg NA, Menchon JM, Zohar J, Veltman DJ: Compulsivity: a new trans-diagnostic research domain for the Roadmap for Mental Health Research in Europe (ROAMER) and Research Domain Criteria (RDoC) initiatives. Eur Neuropsychopharmacol 2016;26:797799

84 Webb CA, Dillon DG, Pechtel P, Goer FK, Murray L, Huys QJ, Fava M, McGrath PJ, Weissman MM, Parsey R, Kurian BT, Adams P, Weyandt S, Trombello JM, Grannemann B, Cooper CM, Deldin P, Tenke C, Trivedi MH, Bruder G, Pizzagalli DA: Neural correlates of three promising endophenotypes of depression: evidence from the EMBARC Study. Neuropsychopharmacology $\quad 2016 ; 41: 454$ 463. 